\title{
Proyectos y efectos: pasado, presente y futuro de la pequeña Isla de Nueva Tabarca (Alicante, España)
}

\author{
Rosario Navalón García* \\ Universidad de Alicante (España)
}

\begin{abstract}
Resumen: Nueva Tabarca, o Isla Plana es un caso de estudio muy interesante para el ámbito de la geografía y la planificación territorial, por los cambios producidos en el tejido urbano y social, así como en el medio natural terrestre y marítimo. Pero lo realmente destacable es que ha sido un lugar de experimentación en el que a lo largo de la historia se han sucedido proyectos urbanísticos impuestos desde el exterior que han modificado su forma y función. Desde la construcción de la ciudad utópica, hasta el boom turístico y la especulación urbanística de final del siglo XX, esta isla es un escenario de pruebas en el que los residentes se han ido adaptando a las condiciones, reflejando las sucesivas tendencias del desarrollo económico de la región.
\end{abstract}

Palabras Clave: Turismo; Patrimonio; Proyectos; Gestión; Sostenibilidad.

Projects and effects: past, present and future of the small island of Nueva Tabarca (Alicante, Spain)

Abstract: Nueva Tabarca, or Isla Plana offers a valuable case study for geography and territorial planning, on account of the changes produced in the urban social fabric, as well as in the greater natural terrestrial and maritimel environment. Nueva Tabarca is outstanding for having represented a place of constant experimentation where urban projects imposed from outside have modified its form and function over time. From the construction of the utopian city to the tourist boom and urban speculation of the late twentieth century, this island has been a testing ground for the successive trends in regional economic development with the residents constantly adapting to the changes.

Keywords: Tourism; Heritage; Projects; Management; Sustainability.

\section{Introducción}

Por su naturaleza las islas han sido consideradas laboratorios interesantes para el estudio del funcionamiento de los sistemas ecológicos y sociales, y más recientemente para la conservación del patrimonio natural y cultural (Mata, 2006:185). A pesar de la posible diversidad para el análisis de las islas, dependiendo de su tamaño, posición, naturaleza y evolución, según Whittaker y Fernández Palacios, 2007, (citado en Hayward, P. 2016), éstas son espacios de hábitat terrestre diferenciados y aislados por un entorno hostil las islas presentan como rasgo común de tratarse de espacios de hábitat terrestre diferenciados y aislados por un entorno hostil ( lo que permite una más sencilla singularización territorial. Sus límites definidos conforman un sistema valioso y a la vez vulnerable debido a dos cuestiones: por una parte, si su tamaño es reducido, la cantidad y variedad de recursos naturales condiciona su capacidad de producción económica y de potenciales intercambios, más aún si se trata de una isla en el espacio mediterráneo con escasa capacidad productiva de su suelo agrícola y con limitación de sus recursos hídricos; por otra, la insularidad en territorios de reducidas dimensiones implica también una capacidad de carga limitada en todas sus acepciones, sea ambiental, social, económica o perceptual. Esto hace que puedan considerarse espacios frágiles y poco aptos para la implantación de actividades altamente consumidoras de recursos naturales y humanos, como el turismo, sin riesgo de generar graves desequilibrios medioambientales y sociales, sobre todo cuando se produce una monoespecialización económica en torno a esta actividad.

Doctora en geografía por la Universidad de Alicante; E-mail: r.navalon@ua.es 
En relación con estas premisas de partida, en este estudio deseamos mostrar el caso de la pequeña Isla de Nueva Tabarca que, situada frente a la región turística de la Costa Blanca (Alicante, España), muestra de forma ejemplar cómo las personas deben adaptarse a las condiciones del medio físico a partir de propuestas y proyectos que a lo largo de los siglos han construido una realidad compleja, pero fundamentalmente dual, que resulta interesante analizar. Sus reducidas dimensiones y su condición insular que le confiere un relativo aislamiento respecto a la península, permiten comprender de forma clara algunos de los procesos sociales y ambientales que configuran los destinos turísticos de buena parte de la costa mediterránea española, pero de una forma simplificada y ciertamente extrema debido a sus particulares factores de localización.

Nos Puede resultar interesante abordar el estudio de esta pequeña isla desde una perspectiva integrada, como el resultado de la interacción humana sobre el territorio que, adaptándose a las cambiantes necesidades de la sociedad a lo largo de la historia, ha generado un singular paisaje cultural, cuya percepción y valor simbólico sigue evolucionando de forma constante. Los paisajes cambian porque son expresión de las fuerzas naturales y culturales en el medio ambiente (Antrop, 2005) y, por tanto, el carácter e intensidad de las mutaciones registradas dependerá de las dinámicas generales dominantes en cada momento histórico. Este autor considera tres periodos de dinámica del paisaje que pueden emplearse para analizar el caso de la Isla de Nueva Tabarca: los paisajes tradicionales anteriores a los cambios que se inician en el siglo XVIII, el paisaje de los siglos XIX y $\mathrm{XX}$, y los nuevos paisajes que denomina postmodernos. Para el caso que nos ocupa, estas tres etapas marcarían tres momentos clave: 1) el estado previo al desarrollo del plan de colonización que cambió para siempre su futuro como enclave fortificado y lugar de control defensivo; 2) el periodo que sucede al ímpetu proyectual que abandona a la sociedad resiente a su suerte y al desarrollo de diversas estrategias para la autosubsistencia y, finalmente, 3) la etapa que refleja las dinámicas del país hacia el desarrollo turístico, dentro del cual pueden diferenciarse a su vez una evolución referida a las tendencias de la demanda y el mercado turístico. El efecto combinado de distintos factores hace que la percepción y valoración del territorio cambie, y también la forma en que se emplean, ordenan y gestionan los recursos disponibles.

\section{La isla de Nueva Tabarca}

Se sitúa en el mar Mediterráneo, frente a frente a las costas levantinas, apenas a 3 millas náuticas $(8 \mathrm{~km})$ al SE de la localidad de Santa Pola y a 10 al sur $(22 \mathrm{~km})$ de la ciudad de Alicante, de quien depende administrativamente. En realidad se trata de un archipiélago compuesto por una isla principal que era conocida en la antigua Grecia como Planesia, Isla Plana para romanos, Nueva Tabarca desde el siglo XVIII, Tabarca para los visitantes o simplemente l'Illa (isla en lengua valenciana) para sus habitantes, a la que rodean los islotes de La Cantera, de La Galera y de La Nao, junto a numerosos escollos (Negre, Roig, Cap del moro, Sabata o Naveta). Presenta una orientación NW-SE y una forma alargada, con un estrechamiento en el tercio oeste, con $2050 \mathrm{~m}$ de longitud y una anchura máxima de $400 \mathrm{~m}$ (Marco, 2012: 16). Se trata de la más grande y la única isla habitada de la región española de la Comunidad Valenciana, con una superficie aproximada de $0,3 \mathrm{~km}^{2}$ y un relieve fundamentalmente plano (de ahí su nombre inicial), entre 5 y $15 \mathrm{~m}$ de altitud sobre el nivel del mar. Presenta una costa de acantilado bajo (la mayoría con una cota de $5 \mathrm{~m}$ ), con algunas playas de cantos rodados y una sola playa de arena que se encuentra en la zona del itsmo. Su terreno se divide en dos espacios: uno en el que se encontraba una pequeña ciudadela amurallada denominada de San Pedro y San Pablo, y en la que en la actualidad se sitúa el espacio urbano y los servicios turísticos rodeadoa en parte por murallas; mientras que en la otra parte, que supone más de dos tercios de la superficie total, se encuentra una extensión sin edificación que se denomina el Campo (campo), dedicada inicialmente a la agricultura y que hoy se encuentra en estado improductivo.

Su clima es mediterráneo seco, es decir, con temperaturas suaves y muy escasa precipitación a lo largo del año. Su temperatura media anual de $17^{\circ} \mathrm{C}$ (máximas de $35^{\circ} \mathrm{C}$ en agosto y mínimas de $5^{\circ} \mathrm{C}$ en enero) y sus lluvias son muy irregulares a lo largo del año, no superando los $300 \mathrm{~mm} / \mathrm{año}$, con una velocidad media del viento no muy alta. Estos rasgos permiten hablar de unas condiciones climáticas excelentes para la actividad turística, pero no tanto para el desarrollo de la vida, ya que la ausencia de agua potable condiciona la viabilidad de una agricultura suficiente, la ausencia de una cubierta forestal y, obviamente, la continuidad del abastecimiento humano. 
Fig. 1: Mapa de localización y toponimia de la isla de Nueva Tabarca.

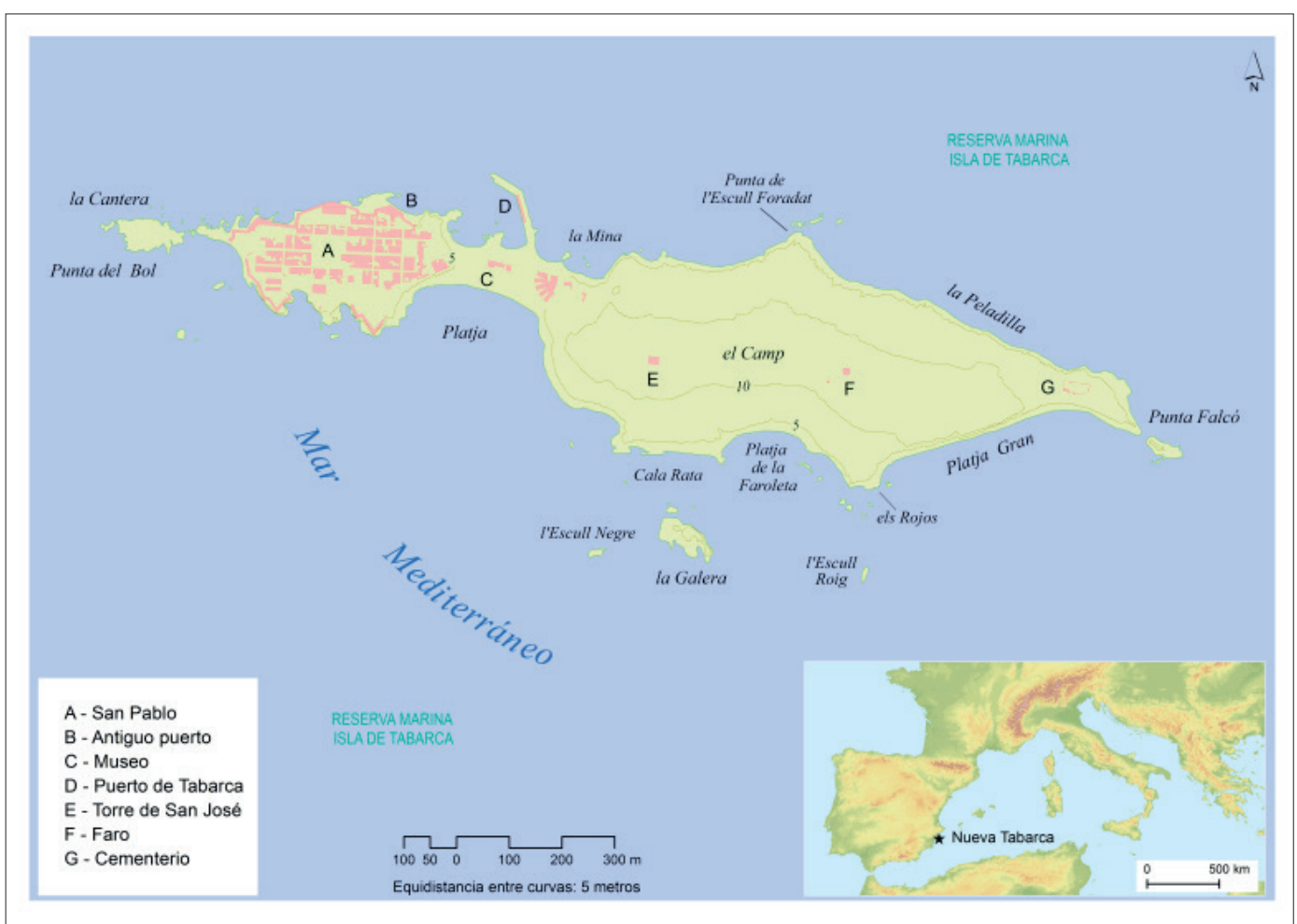

Fuente: Elaboración propia a partir de Cartografía BCV05 (1:5.000), 2005)

En la actualidad está habitada por apenas 55 personas que, aunque mantienen el testimonio de su ocupación pesquera, se dedican fundamentalmente a la actividad turística. Atesora un valioso patrimonio natural y cultural que ha merecido declaraciones para su conservación integral y que componen un conjunto de enorme interés desde muy distintos puntos de vista, sea la investigación, la conservación, recuperación, gestión o desde el aprovechamiento sostenible con fines turísticos.

Se trata de la primera Reserva marina en ser protegida en España, en 1986, por lo que ha servido en años posteriores como modelo de declaración, desarrollo y gestión de nuevos proyectos nacionales e internacionales sobre espacios marinos protegidos. Destaca su Conjunto histórico y Bien de interés cultural desde 1964, máximo reconocimiento por su valor patrimonial en España, para la ciudadela amurallada en tiempos de Carlos III. Este espacio patrimonialrefleja el planteamiento de las ciudades utópicas de época barroca en el siglo XVIII, y fue poblada inicialmente por presos de origen genovés, rescatados por la corona española de su cautiverio argelino en la isla de Tabarka frente a las costas de Túnez. Posee también un interesante patrimonio cultural inmaterial etnológico, tanto en su conjunto urbano como en el resto de la isla, que muestra una intensa relación de la población con un entorno natural hostil para buscar su supervivencia, al que se suman también rasgos de lenguaje diferenciado con algunas variaciones del catalán y reminiscencias de idioma ligur de sus repobladores (Llorca, 2012) que se debe conocer y conservar.

Todos estos rasgos, unido a su historia reciente, configuran un lugar muy interesante, en el que sería conveniente plantear acciones de planificación integral del patrimonio natural y cultural, tangible e intangible. Su singularidad, derivada de su ubicación, naturaleza y devenir histórico, ha sido entendida como espacio de oportunidad en el que desarrollar diversos proyectos y ha sido fuente de inspiración para artistas de todo tipo a lo largo del tiempo. Sin embargo en la actualidad su identidad se desdibuja por un consumo turístico que apenas presta atención a esta riqueza patrimonial y paisajística, para focalizar su visita al disfrute puntual y superficial de su clima y su mar. 


\section{Precedentes históricos para una realidad compleja}

En los días claros desde la isla puede divisarse una parte importante de la costa alicantina, que puede alcanzar $52 \mathrm{~km}$ al N, hasta los acantilados de la Sierra Gelada en Benidorm, y $61 \mathrm{~km}$ hacia el S en el mar Menor de Murcia. Un dominio visual de más de $100 \mathrm{~km}$, que alcanza al círculo montañoso del interior de la provincia de Alicante, y que a lo largo de la historia ha otorgado a esta isla una posición estratégica ante el peligro de posibles invasiones o ataques externos de la costa alicantina. Esta situación, junto a la proximidad de tierra firme y la riqueza de sus aguas desde el punto de vista pesquero, puede entenderse como la razón fundamental de que en ella existan vestigios de presencia humana desde épocas históricas, a pesar de la ausencia de agua potable para suministro humano.

Se han encontrado evidencias de una antigua ocupación de época romana (s. III) y de pecios romanos cargados de ánforas. También de época medieval (s. XII) se tiene constancia escrita de la necesidad de dotar a la isla de construcciones defensivas y de vigilancia para evitar su uso como fondeadero de los barcos piratas procedentes del norte de África, desde donde se lanzaban ofensivas de ataque a la costa de la península, en la que se desarrollaría más tarde (s. XVI) todo un sistema de defensa pasiva en forma de una red de torres de vigilancia, promovida por la corona para avisar a la población del campo de Elche y Alicante ante posibles razias piratas.

En suma, la documentación escrita y arqueológica indica que esta isla fue transitada a lo largo de los siglos y habitada de forma puntual, pero que no tuvo una ocupación permanente hasta la colonización del siglo XVIII (Pérez Burgos, 2012), sin duda debido a que las condiciones de habitabilidad de la isla no parecían las más adecuadas para el desarrollo de poblados autosuficientes.

La suma de circunstancias propició la planificación de una ciudad nueva de carácter militar cuyo proyecto, del ingeniero Fernando Méndez de Ras, puede enmarcarse en los planteamientos utópicos renovados propios de la Ilustración, donde la planificación va más allá de la ciudad e incorpora el territorio, pero lógicamente con un sesgo muy distinto en su función al de la Ínsula de Thomas Moro, por tratarse de una ciudad de carácter militar. Este proyecto se concibe como una actuación única, racional, completa, autosuficiente y autónoma en sí misma, dentro de las posibilidades que permitía el entorno (Varela, 2007), que en este caso se encuentra limitado por su condición de insularidad de muy reducidas dimensiones.

Los factores principales que llevan a diversos autores (Varela, 2007; Pérez Burgos, 2012; Canales, Romero, 2014) a calificarla de proyecto utópico tienen fundamento en varias razones de Estado:

- A mediados del siglo XVIII la corona española define su política respecto al norte de África y plantea la necesidad de establecer una mejor defensa de la ciudad, que aconsejaba la construcción de fuertes adelantados a las murallas. Es así como en 1760 el Gobernador de la plaza mandó la construcción de diversas instalaciones militares en esta isla, para llevar a cabo expediciones con tropa armada y se planifica una guarnición militar en Isla Plana frente a la bahía de Alicante. Por su situación geoestratégica serviría además, para hacer frente a las incursiones corsarias en la costa que tanto perjuicio estaban ocasionando.

- Por otro lado, en el contexto del racionalismo dominante en buena parte de Europa, la creación de escuelas especiales dentro del ejército llevó a la concepción de un cuerpo de técnicos militares, con conocimientos en ingeniería y arquitectura, que dentro de las políticas reformistas de finales del siglo XVIII llevaría a cabo el desarrollo de nuevas poblaciones, predominantemente en territorios deshabitados. De todos ellos, el único de carácter insular fue el núcleo de San Pablo (Canales, 2012) situado en esta isla.

- Otro acontecimiento tuvo lugar en aquellos años: la conveniencia de rescatar del cautiverio argelino a un grupo de 69 familias de origen genovés que habían sido apresados frente a la costa de Túnez en la isla de Tabarka, que estaba bajo bandera española en aquella época. Estas personas fueron liberadas, tras la mediación y el pago de rescate por una orden religiosa, y conformarían la población que hacía falta para colonizar la pequeña y estratégica isla para la que ya se tenía proyecto.

Así pues, de forma coincidente, llegaron ante el rey Carlos III tres cuestiones diferentes pero relacionadas: la lamentable situación de cerca de 300 cautivos cristianos de origen genovés que debían ser rescatados, la necesidad de hacer frente a los ataques de la piratería berberisca de Argel y Túnez, y la propuesta de un gran proyecto militar y civil que desarrollar en la isla de San Pablo alicantina, que sería denominado posteriormente Nueva Tabarca, en alusión a la isla de procedencia de los nuevos pobladores. 
A partir de estas premisas y con todos los permisos pertinentes, Méndez de Ras proyecta una ciudad rodeada por murallas y de forma rectangular, con un plano ortogonal de tradición renacentista, con los ejes organizados conforme a los puntos cardinales, estructurado en torno a tres plazas. En la parte más reducida de la isla se encontraría la ciudad, el asentamiento principal con construcciones exnovo para la población y las tropas. En él se encuentran los elementos del espacio defensivo con las murallas, los baluartes, baterías y defensas en el borde de los acantilados, tres puertas de acceso a la villa, también cuarteles y almacenes para la tropa, así como la edificación de viviendas en parcelas de la misma dimensión para la población civil y para artesanos especializados en diversos oficios complementarios (Varela 2007). Al otro lado del istmo, la parte más extensa de la isla, el campo, sería destinado a la plantación de cultivos articulada por un camino central. En el espacio de la Cantera, de la que se extrajo la piedra para los edificios de la isla, se tenía previsto la construcción de otro fuerte que garantizara la protección del flanco Oeste de la ciudad.

Fig. 2. Plano de Nueva Tabarca de Fernando Méndez de Ras, 1775.

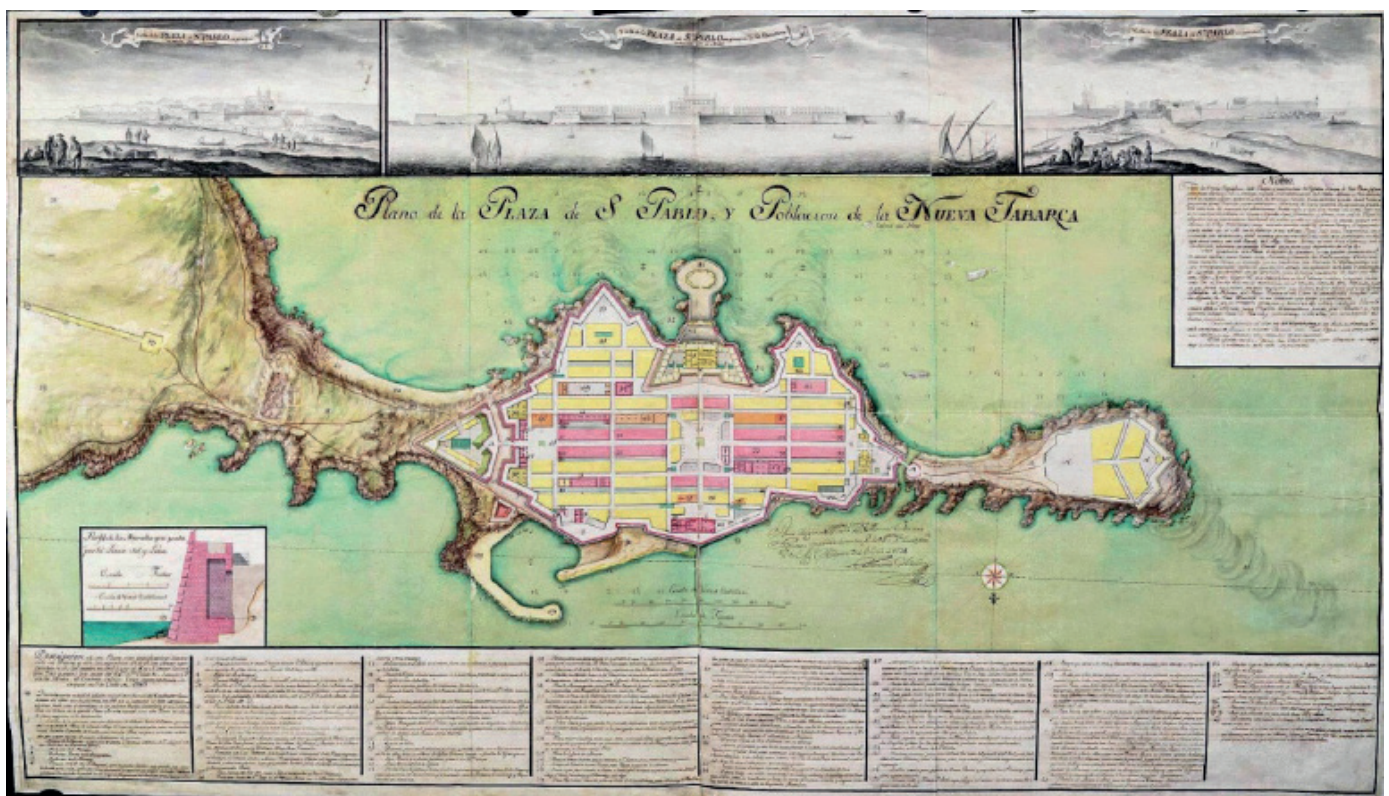

Fuente: Servicio Geográfico del Ejército

Este enclave debía ser autosuficiente y organizarse con una sociedad claramente jerarquizada, pero en su concepción fallaron algunos aspectos fundamentales. Por una parte, la limitación de espacio disponible, la excesiva insolación y el azote de los vientos en esta isla de topografía prácticamente llana, hace muy escaso el suelo fértil, apto para el desarrollo de actividades agropecuarias, fundamentales para la viabilidad sostenible del proyecto. Esta cuestión se ve agravada además por innumerables problemas de abastecimiento, fundamentalmente el de los recursos hídricos necesarios para la población y la agricultura, pero también la ausencia de leña, pues debido a los rasgos geográficos ya descritos la isla no tiene árboles. Aunque desde el proyecto se construyeron pozos y aljibes para almacenamiento de agua en lugares estratégicos dentro y fuera de la ciudadela, la ausencia estructural de lluvias en esta zona hizo necesario el aprovisionamiento con barcos cisterna desde la costa (Pérez Burgos, 2012), lo que dificulta la viabilidad de la propuesta desde el punto de vista económico.

Teniendo en cuenta estas graves dificultades que atañían a los factores básicos de habitabilidad de un territorio, la sostenibilidad del proyecto parecía complicada si no se daba una clara vocación política para su permanencia y ésta falló poco tiempo después. La firma de la paz con Argel (1784) propició la reducción de la piratería berberisca y cambió la orientación de la política de España respecto al Mediterráneo y África. De este modo, la función geoestratégica de la Isla de Nueva Tabarca ya no era 
tan relevante y el importante ejército que debía habitar la isla nunca llegó. La población quedó limitada a los tabarquinos provenientes de Túnez que tuvieron que subsistir en tan duras condiciones de la pesca artesanal y el proyecto nunca llegó a completarse en los términos proyectados. Existen crónicas de viajeros de la época que describen las penalidades y el abandono que padecían las personas que allí vivían (Soler, 2012) y que no podían abandonar por propia voluntad la isla, trasladando la sensación de sentirse presos en aquella isla yerma y sin futuro.

A pesar de este triste final para un proyecto utópico, algo bueno quedó, pues prácticamente todos los recursos patrimoniales de la isla que hoy presentan un claro potencial uso turístico corresponden a esta época: la ciudad fortificada con murallas, puertas monumentales de acceso, baterías de defensa, viviendas, cuartel, caballerizas, bóvedas subterráneas, iglesia, casa para el Gobernador, aljibes y cisternas para la recogida de aguas pluviales, horno para cocer el pan y otros para la cal y el yeso, además de un varadero. Se tiene constancia de que se solicitaron estudios para su demolición, dada la evidente ineficacia de las inversiones realizadas, pero afortunadamente no se informó favorablemente esta destrucción y hoy se puede podemos estudiar este patrimonio como parte de un paisaje cultural que merece la pena conocer y mostrar.

\section{El paisaje tradicional de la isla durante los siglos XIX e inicios del XX}

Tras el abandono del proyecto de ciudad la población se vio obligada a adaptarse a las durísimas condiciones de habitabilidad de la isla, que no contaba con agua, leña, ni suelo fértil. Las descripciones del paisaje que se hacen de esta isla, es que apenas contaba con recursos para la subsistencia. Ello implica que más allá del recinto amurallado, el espacio del Campo -en el área oriental de la isla- se muestra en la actualidad como una gran superficie apenas modificada, formada porprados salpicados de arbustos espinosos xerófilos (adaptados a la escasez de agua) sobre suelos muy poco desarrollados. La escasa capacidad productiva ha propiciado un uso muy reducido por parte de sus habitantes a lo largo de la historia. Así debió mostrarse también entre los siglos XIX y XX, aunque con mayor presencia y uso humano que en la actualidad.

En este espacio únicamente destacan las edificaciones de la Torres de San José, el Faro y una casa de labranza en ruinas y con escaso interés histórico o monumental. Éste es el único elemento que permite describir la precaria economía de subsistencia de la que se obtenían productos para el consumo de los pobladores, aunque se tiene constancia de la llegada de alimentos de la península, antes del abandono por parte de la corona. Según Lozano Quijada (2012) en la década de los años cuarenta del siglo XX, esta edificación formaría parte de un conjunto de casas a modo de granja y establos en torno al edificio central. La carencia de agua hizo necesaria la construcción de aljibes por toda la isla y también en este espacio. Los cultivos principales que marcarían el paisaje de esta parte de la isla que disponía mayor extensión de terreno fueron cereales, como la cebada, trigo y avena, además de la barrilla ${ }^{1}$, junto a algunas higueras y paleras de higos chumbos, al que cerca de la casa acompañaba un pequeño huerto.

En cualquier caso la viabilidad y rentabilidad de estos cultivos era bastante escasa, de modo que con estos condicionantes, parece lógico que la actividad que ha marcado la ocupación y la evolución de los tabarquinos a lo largo de los siglos XIX y XX, haya sido la pesca y en concreto la captura del atún con el empleo del arte de pesca de la almadraba. La vinculación de esta actividad con la población de Tabarca es tal que algunos autores afirman que existe un paralelismo entre la evolución de la población en la isla y el volumen de capturas (Parodi, 2012).

$\mathrm{El}$ arte de la almadraba consiste en un conjunto de redes y barcos que crean una estructura sumergida en la que quedan atrapados los atunes. Se trata de un laberinto de esparto y cáñamo que intercepta y concentra a estos peces migratorios en un espacio cerrado por redes desde donde se capturan de forma masiva. La almadraba de Tabarca era la que mayor volumen de capturas registraba en toda la provincia y se colocaba frente a la isla de la Galera. Empleaba prácticamente a todos los habitantes de la isla en las distintas tareas: de captura, elaboración y reparación de las redes y estructuras, mantenimiento de las embarcaciones, y preparación y venta de la pesca, aunque por falta de agua y salinas la pesca se trasladaba íntegramente a la costa peninsular. Se habla de un apogeo máximo en volumen de capturas y población implicada a final de los años 40 del siglo XX, hasta su declive y cierre definitivo en 1960, cuando esta almadraba era ya la única que quedaba en la costa alicantina.

Aunque en la actualidad ya no se practica este arte de pesca, aún hoy se conservan topónimos en la isla que hacen mención a las tareas asociadas a esta actividad. Además existen numerosas historias que, entre la leyenda y la historia real, narran las proezas de estos marineros, que en alguna ocasión 
debieron enfrentarse a animales de gran tamaño como cetáceos o tiburones (Parodi, 2012), y que podrían ser consideradas parte del patrimonio intangible de la isla que merecería la pena conservar.

Fig. 3: Evolución de la población de Nueva Tabarca (1769-2015).

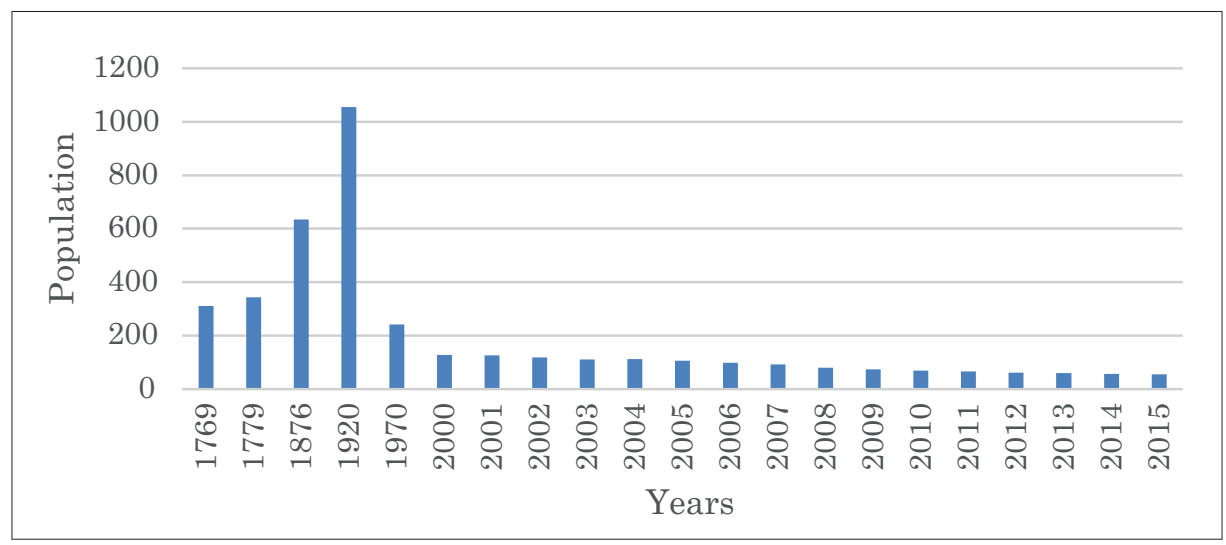

Fuente: Elaboración propia a partir de datos del Instituto Nacional de Estadística.

Tras la desaparición de este arte de pesca, se ha producido un paulatino despoblamiento hasta llegar a nuestros días, con apenas 55 habitantes censados, de los cuales en temporada invernal apenas viven entre 10 y 15 personas ${ }^{2}$, pues residen en Santa Pola y otras localidades en tierra firme hasta la llegada del verano, cuando la población se multiplica considerablemente, sin contar con los miles de visitantes que llegan durante los meses estivales. En la década de los años 60 del siglo XX, el declive de la isla se agravó, no sólo por la pérdida de población, sino por la evidencia de carencias infraestructurales como la ausencia de abastecimiento de agua, energía eléctrica y un saneamiento adecuado en la isla.

La síntesis de este periodo es que el paisaje urbano inacabado del proyecto del siglo XVIII queda prácticamente intacto, y el área de el Campo es el que varía de un modo más evidente respecto al paisaje natural originario por la aparición de una actividad agropecuaria raquítica que debe adaptarse a unas condiciones ambientales adversas, sin lograr una productividad suficiente.

El entorno que más varía en la isla es el que se relaciona con el espacio portuario y marítimo por la relevancia de la actividad pesquera de la almadraba. Sin embargo, también este uso resultó efímero ante la llegada de una actividad que acabaría arrollando al resto de ocupaciones de los habitantes de la isla: el turismo.

\section{Una nueva etapa para el desarrollo de la isla de Tabarca: el turismo como "solución"}

A falta de otras opciones de subsistencia e inmersos en el contexto de la región turística de la Costa Blanca española situada a pocos kilómetros de distancia, algunos de los pescadores adecuaron sus embarcaciones para nuevos usos recreativos o compraron naves nuevas para realizar traslados para los visitantes turistas que empezaban a interesarse por esta isla, atraídos por el sol y la playa, pero también por prácticas de pesca deportiva. Se repararon viviendas antes vacías y se abrieron casas de comidas y algunos comercios para atender a esta incipiente demanda de visitantes. También se produjo la ampliación del puerto en 1944 que permitiría la llegada con mayor comodidad de un mayor número de embarcaciones. Pero todo esto, como en muchos otros destinos de la costa peninsular, se produjo sin planificación u ordenación previa, a pesar de la existencia de los mecanismos legales necesarios (Navalón, 1995).

En estos años en que se inicia el desarrollo turístico en todo el litoral español, el marco legal de ordenación territorial y urbanístico que poseía el municipio de Alicante se limitaba a un Plan urbanístico de Alineaciones. En él que se establecían usos del suelo para todo el territorio, pero se proponían a partir de una zonificación concéntrica en torno al Suelo Urbano, con una propuesta poco adaptada a las necesidades del municipio o a una planificación coherente con los recursos disponibles que parecía 
responder más a un crecimiento espontáneo que a un plan de futuro (Navalón, 1995). Estos planes dependían del Estado central de la nación, de forma que el proceso de aprobación de los nuevos planes urbanísticos que debía marcar las pautas del desarrollo futuro acordes con la Ley del Suelo de 1956 resultaba lento y dificultoso. Es por ello que en Alicante, como en otros lugares de España, era frecuente la propuesta de Planes Parciales ${ }^{3}$ que se adelantaban a una ordenación integral de territorio.

Así estuvo a punto de ocurrir en la isla de Tabarca en 1962, cuando desde Madrid una empresa planteó la compra de dos terceras partes de la isla para desarrollar el macro-proyecto turístico "Tabarca Island”. Según recogen los documentos presentados por la mercantil que tomaba la iniciativa, se solicitó al ayuntamiento realizar los estudios previos para desarrollar a posteriori un Plan Parcial que ordenaría todo el terreno insular. Planteaba comprar los solares correspondientes con "la finalidad de llevar a cabo un planeamiento urbanístico total de la Isla, para dotarla no solamente de las necesarias instalaciones (tales como agua, electricidad, etc.) que la vida moderna exige para un normal y adecuado régimen de vida y saneamiento de la población, sino también restaurar y conservar los elementos de interés artístico e histórico existentes, reconstruyendo y realizando el proyecto existente de fecha mil setecientos setenta obra del Ingeniero Militar D. Fernando Méndez, [...]”. Proyectaba además la construcción de un club de yates, esquí acuático, pistas de tenis, cuadras, bolera, o helipuerto, entre otros servicios (Parodi, 2015) que, junto a la construcción de alojamiento para 800 personas, era reflejo de una tendencia desarrollista en la surgieron otros grandilocuentes proyectos en la Costa Blanca, que finalmente no llegaron a realizarse.

\section{Fig. 4: Plan de ordenación del proyecto Tabarca Island.}

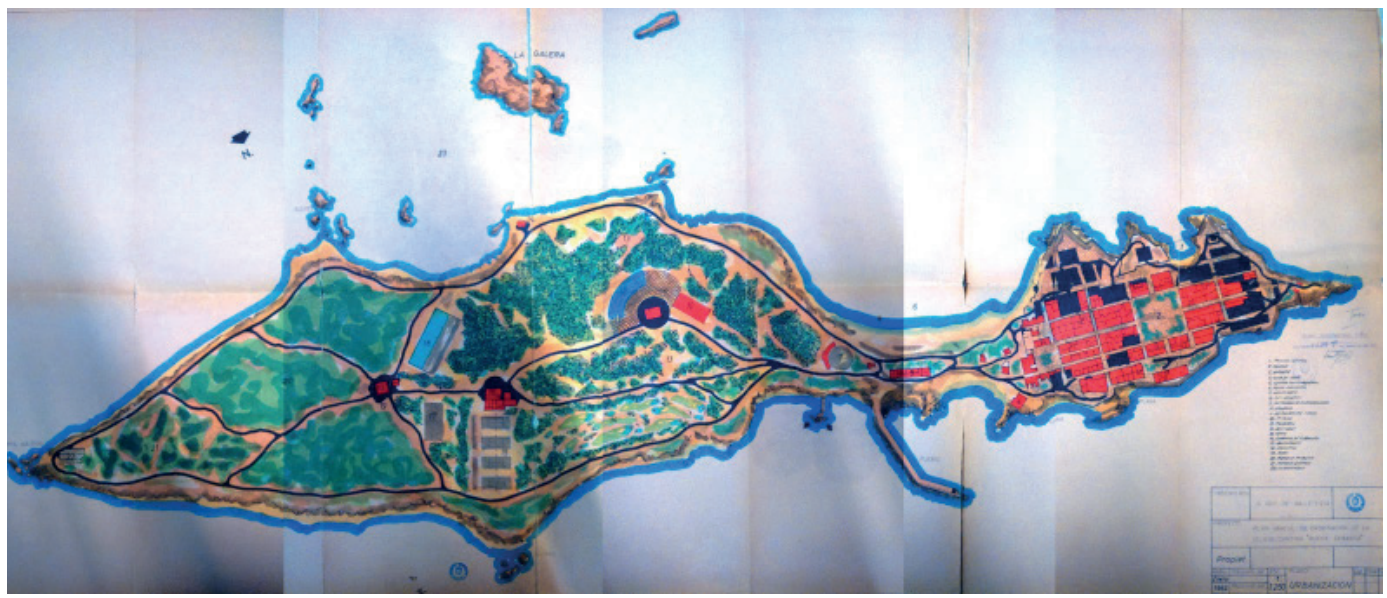

Fuente: Expediente Tabarca Island (Archivo Municipal de Alicante). Tomado de Parodi (2015)

En este caso, entre otras razones, la demora que supuso que algunos particulares vinculados a la propiedad del suelo desearan tomar iniciativas similares, para obtener directamente el beneficio de este proyecto, supuso una traba burocrática que, aunque fue desestimada, sirvió para enfriar las ansias transformadoras de la mercantil que afortunadamente no se ejecutaron, pues supondrían la alteración drástica de su paisaje natural y del patrimonio histórico.

Este proyecto es buena muestra de las presiones urbanizadoras que, procedentes desde empresas foráneas o desde los propietarios del suelo, sufrieron multitud de parajes de indudable valor paisajístico que finalmente acabaron desapareciendo o se transformaron de forma drástica. En la provincia de Alicante con predominio de clima seco y mar cálido, con una rentabilidad agrícola del suelo heterogénea, el turismo parecía ser la solución a los problemas de los residentes y también así se percibía en la isla de Nueva Tabarca, ávida de que se le prestase atención por parte de los poderes públicos. Probablemente a raíz de este proyecto se concibió la declaración del espacio fortificado de Tabarca como Conjunto Histórico-artístico en 1964, y un poco más tarde la declaración de su entorno marino como la primera Reserva Marina de España en 1986, lo que junto con la esperanza del desarrollo del turismo, conforman los tres vectores que podrían marcar una nueva dirección para el desarrollo socio-económico de la isla. 


\subsection{La reserva marina de Tabarca: un ejemplo pionero de gestión en dificultades}

Desde mediados del siglo XX las principales actividades económicas en esta isla fueron la pesca tradicional y el turismo, ambas con presencia creciente tanto en tierra como en el espacio marítimo que circunda la isla, por lo que parecía oportuno buscar la compatibilización de ambas funciones, de forma que sólo se permitieran artes y aparejos muy selectivos dentro del área protegida y en determinados sectores, y sólo para los pescadores de la cofradía de pescadores de Tabarca.

En este escenario de tensión entre la conservación de las prácticas tradicionales y de desarrollo de nuevas funciones vinculadas al uso recreativo y turístico, en 1986 el entorno de la isla de Tabarca, con $1400 \mathrm{ha}\left(14 \mathrm{~km}^{2}\right)$, es declarado Reserva Marina, con el objetivo de proteger los ecosistemas y especies de la zona, así como para gestionar adecuadamente los recursos de la pesca tradicional (Ramos y Bayle, 1990). Aunque con escasa relevancia desde el punto de vista cuantitativo, con una quincena de embarcaciones censadas en la cofradía con tripulaciones de 2 o 3 personas, desde entonces y hasta ahora en Tabarca se practica todavía la pesca tradicional, actividad reconocida como respetuosa con el medio y sostenible. Tras su declaración como reserva marina protegida, se ha comprobado que una más adecuada gestión de los recursos marinos y de la pesca es capaz de aumentar la producción de las pesquerías desarrolladas alrededor del área protegida, pues el cese o reducción de las captura dentro de la reserva produce un aumento en abundancia y tamaño de los ejemplares al no tratarse de espacios cerrados (Forcada, 2012).

Además de sus objetivos para fomentar la pesca sostenible y respetuosa, la gestión de Reserva marina lleva implícita la labor de información y sensibilización de la población local, o la creación de infraestructuras para complementar su tarea con la investigación. También impulsó la adecuación del edificio de Faro como centro de investigación, la protección de los fondos marinos y el impulso de campañas de educación ambiental, entre otras funciones abiertas a todo tipo de colectivos, tanto residentes como externos. Evidentemente, todas estas labores necesitan financiación suficiente, sea para la dotación de personal adecuado y el mantenimiento de inmuebles, o para la coordinación y apoyo por parte de todas las administraciones responsables a distintas escalas. Sin embargo, lamentablemente en los últimos años los recortes asociados a la crisis económica, pero sobre todo la falta de voluntad política, están afectando a la efectividad de sus objetivos, apuntando una deriva que no parece la más adecuada para el mantenimiento de un proyecto de más de 30 años y que había sido tomado como ejemplo de gestión en muchos otros lugares.

\subsection{La protección del patrimonio cultural en un contexto de presión inmobiliaria turística}

Como se comentó, casi de forma simultánea a la presión transformadora del turismo, en 1964 el indudable valor patrimonial anterior a la colonización y el conjunto resultante del proyecto de construcción defensiva de Nueva Tabarca del s. XVIII, fue reconocido y declarado como Conjunto histórico artístico. No obstante, su consideración de facto tenía poca trascendencia desde el punto de vista de la conservación y gestión del patrimonio, por la escasa precisión de sus determinaciones sobre los edificios que se debía proteger, y sobre cómo debía hacerse (Martínez Sanmartín, 2012). Tras los cambios legislativos en materia de protección en la escala nacional y regional (1985 y 1998), la isla pasó a tener la consideración de Bien de Interés Cultural (BIC) ${ }^{4}$ con categoría de conjunto histórico, al que por la evolución legal se añadieron también los bienes y valores inmateriales de carácter etnológico.

A pesar de la importancia de este reconocimiento, hay que recordar que para la protección efectiva del patrimonio de la isla no basta sólo con la declaración formal de 1964, sino que ésta debía ser completada con la redacción de un Plan Especial de la Isla de Tabarca, que sería un documento de ordenación y planificación detallada que completaría al planeamiento municipal. Se trata de un trámite fundamental pero, por varias razones, se aprobó finalmente en 1984, veinte años después, a pesar de que comenzara su redacción en 1969 ante la presión de posibles urbanizaciones turísticas en la isla.

Aunque fuera necesario proteger el conjunto de forma integral, de todas las construcciones del proyecto inicial, sólo se protegieron los elementos más relevantes como las murallas, casa del gobernador y la iglesia, dejando de lado la salvaguarda de las viviendas originales de los residentes y del patrimonio todavía vivo, en todas sus manifestaciones -muebles, inmuebles e inmateriales-. Por ello se han ido perdiendo, en paralelo a las formas de vida tradicional, sustituidas por costumbres y usos que se adaptan mejor a las necesidades de la vida moderna y de la actividad turística.

En todo este periodo desde el despegue del turismo hasta nuestros días, la fiebre edificatoria del turismo residencial de los destinos de la Costa Blanca alcanzó a la isla propiciando la paulatina sustitución de las viviendas tradicionales por nuevas construcciones de volumen y estructura distinta, lo que ha afectado a la homogeneidad del conjunto y a la conservación de su esencia. 
Fig. 5: Recursos patrimoniales del Conjunto histórico-artístico protegido.

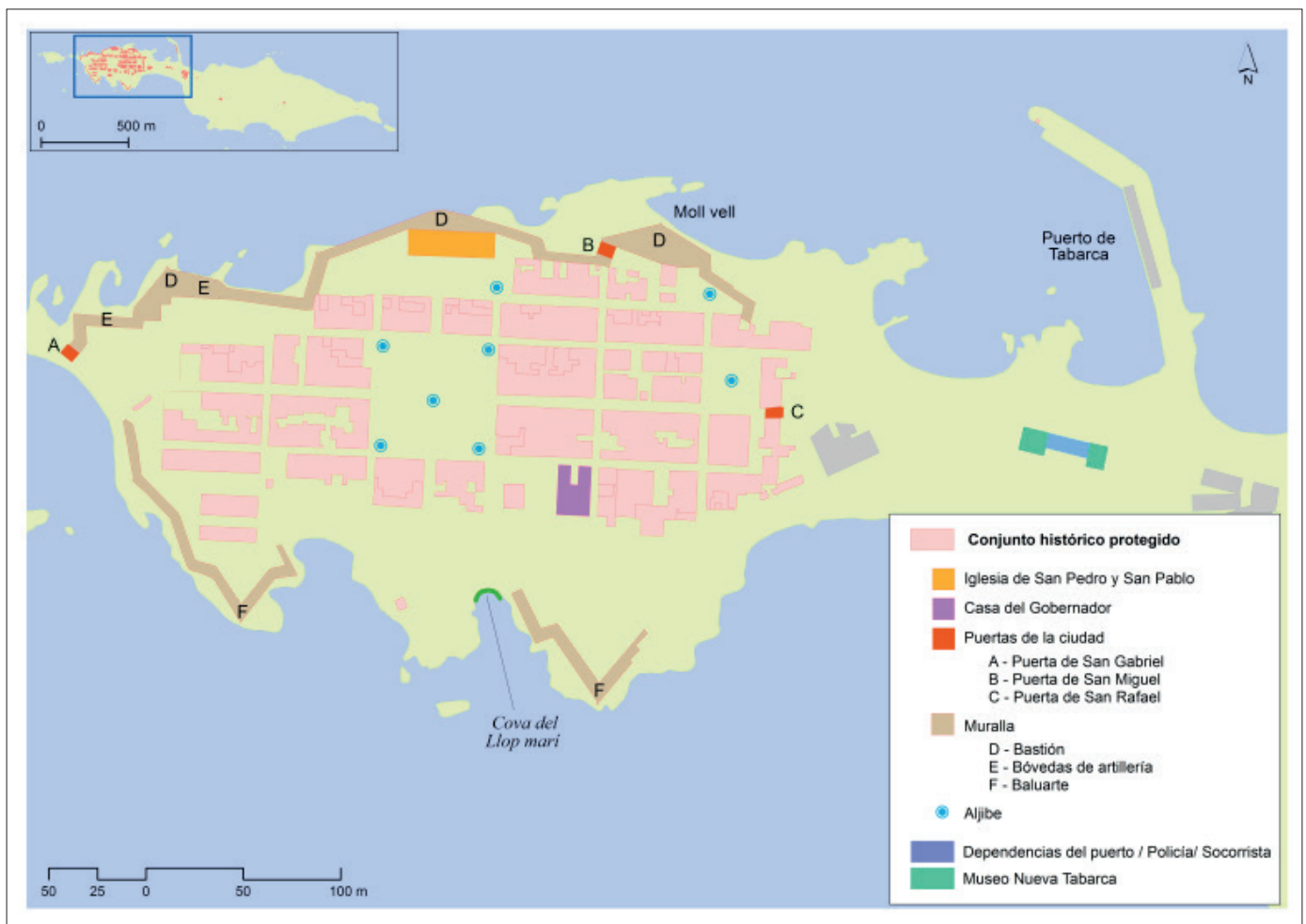

Fuente: Elaboración propia

Aunque no se trataba del primer proyecto de construcción vinculada al turismo, pues hubo precedentes que no llegaron a ejecutarse, la expresión más clara de esta presión urbanizadora se dio en 1994, con la aprobación de un proyecto de edificación que incorporaba nuevas manzanas dentro del recinto fortificado. La ausencia de una normativa reguladora clara que definiese las actuaciones permisibles y el contexto global de desarrollo turístico-inmobiliario en el Mediterráneo español, acabó desembocando en el abandono y modificación de la arquitectura tradicional de las viviendas del poblado por otras tipologías poco o nada respetuosas con las estructuras previas, desvirtuando el conjunto. Incluso se llegaron a ejecutar propuestas en forma de bungalows adosados que rompen con la armonía inicial del conjunto. De hecho, aprovechando la dificultosa tramitación de la ordenación urbanística del municipio de Alicante (de quien depende administrativamente la isla), incluso se llegó a edificar un conjunto de chalets de forma ilegal, que incumplían la protección de la Ley de Costas y que, afortunadamente, han sido recientemente demolidos.

En esta misma línea de aparente improvisación, las propuestas urbanísticas impulsadas desde la administración municipal alicantina para mejorar el espacio público de la isla, tampoco parecen partir de una reflexión respetuosa con la protección integral. De hecho, el proyecto de adecuación y urbanización de la zona del istmo, también de 1994, resultó bastante controvertida en su momento con contestación por parte de colectivos preocupados por la conservación. En esta actuación que intervenía en el espacio del istmo, en el que sólo existía la construcción de la antigua almadraba, que podría haber sido restaurado pero que se demolió, se proyectó un edificio dedicado a distintas dependencias con funciones administrativas y de servicios, en el que se encuentra también el Museo Nueva Tabarca, con una propuesta volumétrica que contrasta de forma drástica con el conjunto patrimonial. En este espacio se añadieron también una estructura en forma de abanico para albergar un grupo de restaurantes cuyo conjunto y volumen, como en el caso anterior, rompe con la línea de horizonte preexistente, que se situaba en una cota más baja entre los dos espacios laterales, de la isla alterando así la percepción del conjunto. 
En respuesta a éstas y otras presiones transformadoras, y con la intención preservar el patrimonio insular de futuras acciones irreversibles, en 2001 se suspendió la vigencia del citado Plan Especial de 1984 hasta la entrada en vigor de una nueva ordenación, que todavía hoy -en 2016- no se ha logrado aprobar por diversas razones políticas. Lo que parece evidente es que el nuevo Plan Especial para la isla de Tabarca debería responder a un criterio de ordenación integral, que articule acciones para la protección del patrimonio natural y cultural y del paisaje, propiciando un uso adecuado de los recursos territoriales, en el que la gestión del turismo contribuya al desarrollo sostenible desde el punto de vista ecológico, económico y social.

\section{El turismo en la isla de Tabarca hoy: luces y sombras en la gestión del territorio insular}

En la actualidad la isla de Nueva Tabarca se dedica casi exclusivamente a la actividad turística, con el mantenimiento testimonial de la pesca por parte de algunas personas. Su proximidad a la costa turística alicantina, que conforma casi un continuo urbanizado de carácter turístico en el que se sitúan destinos maduros dedicados al producto sol y playa como Benidorm, supone un factor que puede entenderse de forma dual, tanto positivo como negativo. Por una parte, esta cercanía permite la provisión de recursos o servicios y, obviamente, favorece la llegada de excursionistas que pasan unas horas en esta isla, para contemplar sus elementos patrimoniales o disfrutar de una experiencia singular en la única isla habitada de la región. La otra cara de esta proximidad es que esta cercanía ha propiciado una actitud por parte de los residentes, visitantes y de la propia administración de temporalidad o estacionalidad que repercute en la ejecución de las actuaciones necesarias, con propuestas provisionales o ajustes temporales.

Podemos calificarla de una isla de contrastes: casi desértica en invierno con menos de una veintena de personas, pero saturada en la temporada alta turística con días que superan las 3500 visitas. Presenta una parte de su territorio construido y humanizado frente a la otra con vacío poblacional total y predominio de una cubierta vegetal silvestre. Parte de un proyecto de partida completamente planificado de forma integrada y una realidad actual en la que se van solapando planes sucesivos sin aparente coordinación y orden. Una isla en la que no existen carreteras pues no hay tráfico rodado más que de pequeños vehículos de servicio, frente a un puerto en el que en época estival se da una notable congestión de barcos o catamaranes que realizan trayectos desde los puertos de Santa Pola o Alicante entre otros, además de multitud de embarcaciones particulares, lanchas y yates que atracan en las áreas de fondeadero permitidas por la Reserva marina. En resumen un lugar de interés desde el punto de vista natural, cultural, social y económico, como pocos.

Cuando se han cumplido ya más de 50 años desde la declaración como Conjunto histórico artístico en 1964, en la isla queda mucho por hacer. Ciertamente, se han se ha conseguido completar la infraestructura para la dotación de agua potable, electricidad y depuración, aunque muy recientemente, bien entrado el siglo XX, pero todavía están en proceso distintos proyectos impulsados por parte de la administración alicantina en coordinación con los entes nacionales o regionales implicados, como el de Medio ambiente, Cultura, Costas, o interior (defensa) entre otros.

Desde el punto de vista patrimonial se han completado acciones previstas tiempo atrás, como la pavimentación del suelo del centro histórico, la restauración de varios tramos de muralla y baluartes deteriorados por los sucesivos temporales, la limpieza de las bóvedas de artillería para que puedan visitarse, o la recuperación de la iglesia de San Pedro y San Pablo, aunque no ha llegado a completarse la reconstrucción de la casa del cura o de la escuela que se situaban anexas a esta construcción. A comienzos del siglo XXI se inauguró el museo de la Isla llamado de Nueva Tabarca (2002) con la intención de difundir el patrimonio integral y la historia de la isla; y apoyado en éste se abrió también el Centro de Educación Ambiental CEAM Tabarca (2006) con la finalidad de colaborar en la educación ambiental y formación de cualquier colectivo interesado en la salvaguarda de los valores patrimoniales.

También se han llevado a cabo algunas actuaciones de señalización turística en el espacio del Campo en el que se ha señalizado uno de los tres senderos señalizados, en este caso de naturaleza medioambiental que recorre todo el perímetro de esta parte de la isla. A éste acompaña el sendero urbano en el interior de la ciudadela, y un tercero submarino proyectado para la visita de los ricos espacios marinos de su entorno.

Podría parecer que se ha iniciado una nueva época en la que se promete la inmediata aprobación de un nuevo Plan Especial de la Isla de Tabarca y la reconstrucción de otros inmuebles en ruinas en el espacio deshabitado del Campo, como la casa de labranza, la posible recuperación para usos culturales de la Torre de San José ahora propiedad del Ministerio de Interior o la dotación de contenidos de interés 
público del edificio de faro de la isla. Sin embargo, a nuestro entender la concepción de las inversiones no es totalmente acertada, pues a pesar de proponer actuaciones necesarias creemos que se está desatendiendo la vertiente de la gestión y mantenimiento de las acciones.

\section{Fig. 6. Distribución de la oferta turística de Nueva Tabarca.}

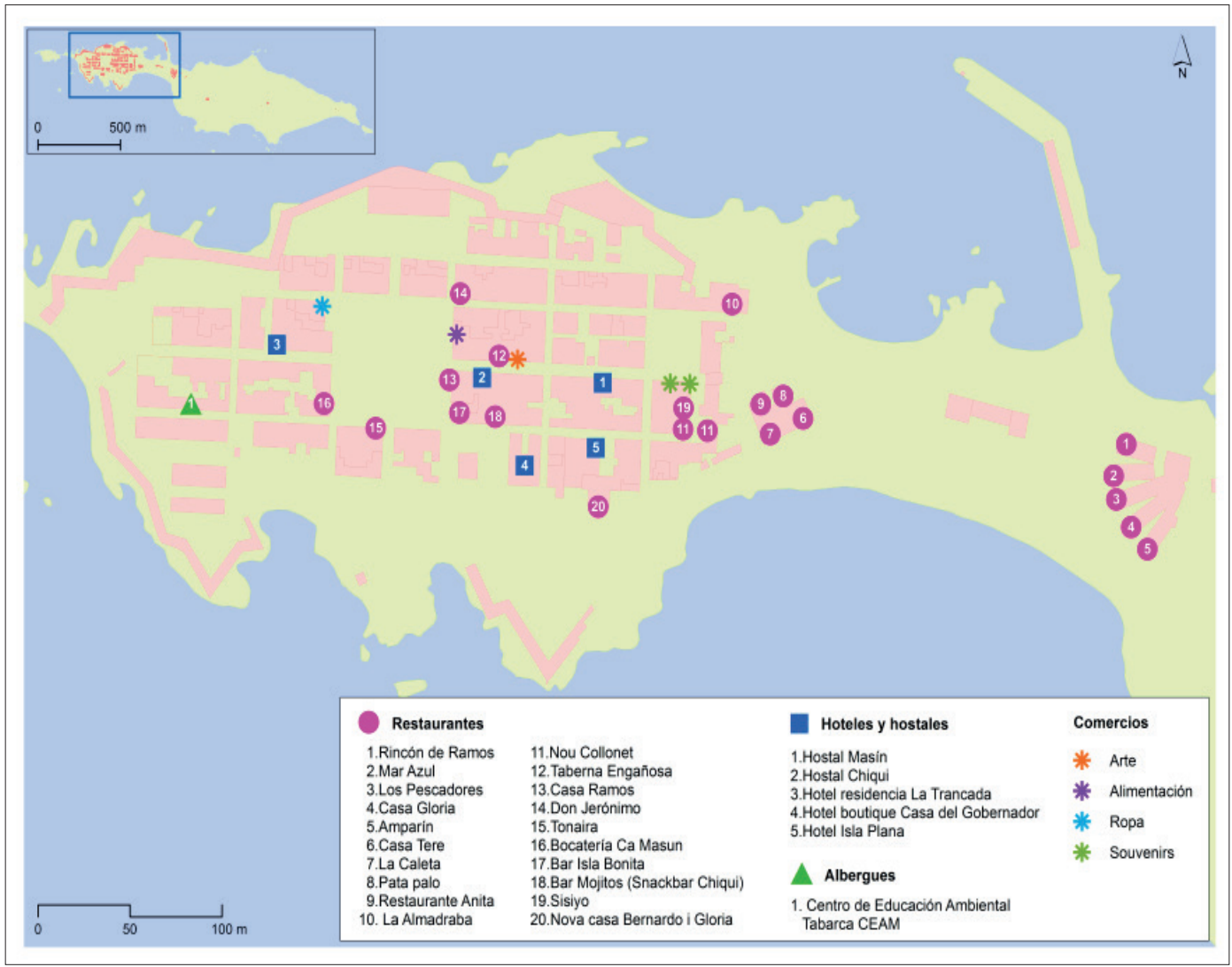

Fuente: Elaboración propia

Si analizamos la actual estructura de la oferta turística de Tabarca varios datos llaman la atención:

- La oferta hotelera, que no alcanza las 100 plazas registradas, en tres hoteles y dos hostales, es escasa para el interés del patrimonio insular y puede calificarse de categoría baja o media. Cuenta también con un albergue con capacidad para 32 plazas aunque éste se orienta a una clientela de sesgo fundamentalmente educativo. Pero quizás lo más destacado es la proliferación en los últimos años de una oferta de viviendas en alquiler que en su mayoría no aparece en los registros de oferta turística, por lo que no debe someterse a inspección turística ni a los controles de calidad y servicios de una oferta regulada. Puede encontrarse en la web una decena de viviendas que ofrecen más de 76 plazas, de las cuales sólo dos se encuentran en una empresa de carácter turístico. El resto se pueden encontrar en la plataforma de economía colaborativa Airbnb, (pues se muestran como alquiler entre iguales). Según todos los indicios por el trabajo de campo realizado, a estas viviendas en alquiler podrían unirse muchas otras que en temporada alta son cedidas o alquiladas de manera informal o directamente entre particulares.

En suma, Tabarca cuenta con una oferta de alojamiento poco regulada y de escasa calidad, pues más de un tercio de ésta no se encuentra en los canales normales de comercialización. Pero además 
si tenemos en cuenta la reducida población residente en el espacio insular, obtendríamos una tasa de función turística ${ }^{5}$ superior a 372 , lo que según la nomenclatura de Defert indica que Tabarca es un centro especializado en la recepción de turistas que multiplica casi por tres las cifras de Myconos o Santorini (Fernádez-Latorre, Díaz, 2011). Este balance resulta más llamativo si realizamos la relación de plazas de alojamiento por $\mathrm{km}^{2}$ pues la tasa alcanzaría una cifra superior a 683 plazas $/ \mathrm{km}^{2} \mathrm{y}$ por tanto cercana a la saturación.

- En relación con la oferta de restauración, la isla cuenta con 20 restaurantes distintos que ofrecen casi exclusivamente cocina mediterránea con platos de inspiración marinera, como "el caldero" que pueden ser considerados en algunos casos como parte del patrimonio etnográfico insular. La capacidad de acogida total de estos restaurantes supera las 2088 plazas, lo que puede valorarse positivamente. Sin embargo, la estandarización y escasa variedad de los menús ofrecidos, que responden en principio a una demanda que busca ese tipo de servicio, comienza a ser calificada de mejorable por una clientela que busca productos más singulares y un servicio más personalizado.

- El transporte, elemento fundamental para el turismo de Tabarca se realiza en barcos o catamaranes con procedencia mayoritaria desde el puerto de Santa Pola y de Alicante, con una frecuencia en temporada alta de un barco cada hora, aunque también estacionalmente desde Benidorm, Guardamar y Torrevieja. Según las empresas que realizan estos servicios, el número de visitantes que llega en los días estivales de máxima afluencia puede superar los 3500 visitantes, entre los meses de junio y septiembre. Ello implica que la capacidad de carga física y perceptual en la parte construida de la isla, que no supera $0,1 \mathrm{~km}^{2}$, ofrece resultados muy abultados que indican niveles que precisaría la puesta en marcha de estrategias de descongestión y planificación sostenible.

- Finalmente, lo más relevante a nuestro entender se relaciona con la oferta turística en torno a los recursos patrimoniales, tanto naturales como culturales. Se ha descrito y reiterado el indudable interés de estos elementos que han merecido la máxima declaración de protección, y debería resultar obvio que las personas que visitan la isla lo hacen motivados por lo que ellos significan en el plano histórico y natural. Sin embargo, puede decirse que más allá de las instalaciones del museo Nueva Tabarca y de los recientes paneles de señalización de los senderos natural y urbano, no existe ningún servicio turístico que los interprete, pues el propio museo no se encuentra abierto de forma continuada y no existe un servicio de guiado cultural o natural en la isla para las personas que pudieran solicitarlo. De este modo, sin conocer sus evidentes potencialidades, al llegar a la isla los visitantes sólo pueden ir a la playa, pasear, contemplar el paisaje y si lo desean comer en alguno de los restaurantes, pero no tienen la posibilidad de disfrutar de una experiencia en torno al patrimonio insular, lo que consideramos es una de las principales debilidades del modelo turístico tabarquino.

\section{Conclusiones}

En el desarrollo de estas páginas se ha mostrado cómo a lo largo del tiempo la isla de Nueva Tabarca ha sido objeto de varios proyectos para desarrollar en su reducida extensión propuestas integrales que buscaban aprovechar su estratégica situación. Desde la concepción de una ciudad casi utópica que fue el germen de la actual Nueva Tabarca, abandonada al poco tiempo de iniciar su construcción dejando a sus pobladores a su suerte, hasta el proyecto de un destino turístico sostenible y respetuoso con el medio en un contexto económico y político algo convulso, pasando por actuaciones que buscaban la transformación drástica de su paisaje con fines turísticos en plena época desarrollista.

En todos los casos, se han obviado o minusvalorado la importancia de factores de desarrollo tan importantes como el abastecimiento de agua y energía, la gestión de los residuos y el saneamiento, la mejora de la accesibilidad externa, interna e intelectual a los recursos de atracción que permanecen cerrados o no son interpretados, o la necesidad de plantear un desarrollo turístico en el que más allá de la reconstrucción y señalización de los elementos de atracción es preciso trabajar en la gestión de éstos a través de una suficiente dotación de personal cualificado, y, por supuesto, de un presupuesto adecuado para el mantenimiento y desarrollo permanente de las actividades.

Para el desarrollo sostenible de la isla el planteamiento ha de ser integral, tanto en términos ambientales, como también económicos y sobre todo sociales, de una forma equilibrada capaz de satisfacer a residentes, visitantes, inversores y responsables de su viabilidad. Para lograrlo, sin duda, será necesario poner en marcha un proceso de planificación coordinada a distintos niveles administrativos y desde diferentes perspectivas, pero sobre todo se ha de procurar que el diálogo entre todos los agentes implicados sea 
fructíferoSólo así se conseguirá aprobar el Plan Especial de la Isla de Tabarca que tanto necesita, y sólo con propuestas realistas y consensuadas es posible la protección de su patrimonio. Pero con los planes no basta, será imprescindible además la definición de una serie deherramientas de gestión adecuadas que sean capaces de promover un desarrollo duradero a partir de un uso turístico y recreativo responsable.

\section{Bibliografía}

Antrop, M.

2005. "Why Landscapes of the Past are Important for the Future", in Landscape and Urban Planning 70(1-2):21-34

Canales, G.; Romero, O.

2014. "La población de Nueva Tabarca, Un proyecto ilustrado de fortificación insular", en Canales, G.; Pérez, J.M; Lozano, F. (2014) Nueva Tabarca, un desafío multidisciplinar. Instituto Alicantino de Cultura Juan Gil-Albert: 85-108.

Defert, P.

1967. Le Taux de Fonction Touristique. Mise au point et critique.5. Les Cahiers du Tourisme. Serie C, $\mathrm{n}^{\circ} 5.33 \mathrm{p}$

Fernández-Latorre F. M.; Díaz del Olmo, F.

2011. "Huella ecológica y presión turística socio-ambiental. Aplicación en Canarias". Boletín de la Asociación de Geógrafos Españoles, 57: 147-173

Forcada, A.

2012. "La pesca artesanal en la Reserva Marina de Tabarca: una alternativa sostenible", en Canelobre, Instituto Alicantino de Cultura Juan Gil-Albert, 60: 182-195.

Hayward, P.

2016. "Towards an expanded concept of island studies", in Shima: The international journal of research into island cultures, 10: (1): 1-7.

Llorca Ibi, F.X.

2012. La llengua tabarquina: de Gènova a Alacant" en Canelobre, Revista del Instituto Alicantino de Cultura Juan Gil-Albert, 60: 206-215.

Lozano Quijada, A.A.

2012. "Entre el mar y el cielo, el tercer hito del campo", en Canelobre, Instituto Alicantino de Cultura Juan Gil-Albert, 60: 196-205.

Marco Molina, J.A.

2012. "Aspectos geográficos del entorno físico: morfología de la costa de Nueva Tabarca", en Canelobre, Instituto Alicantino de Cultura Juan Gil-Albert, 60: 14-31.

Martín, B.

2003. "La imagen turística de las regiones insulares: Las islas como paraísos", en Cuadernos de Turismo, 11: $127-137$

Martínez Sanmartín, L.P.

2012: "El patrimonio como proceso social. Acerca de la isla de Nueva Tabarca", in Tabarca. Utopía y realidad, Canelobre, Revista del Inst. Alicantino de Cultura Juan Gil-Albert.60: 373-383

Mata Olmo, R.

2006. "Desarrollo sostenible, insularidad y gobierno del territorio: La experiencia del PTI de Menorca", en Boletín de la Asociación de Geógrafos Españoles, 41: 183-198

Navalón-García, R.

1995. Planeamiento urbano y turismo residencial en los municipios litorales de Alicante. Ed. Generalitat Valenciana. Instituto de Cultura Juan Gil-Albert. Alicante.

Parodi Arróniz, A.

2012. "La almadraba de Tabarca: un medio de vida entre la historia y la leyenda", en Canelobre, Instituto Alicantino de Cultura Juan Gil-Albert, 60: 162-181.

Parodi Arróniz, A.

2014. "El histórico problema del agua y la sanidad en Tabarca", online http://lafogueradetabarca.blogspot. com.es/2014/06/el-historico-problema-del-agua-y-la.html. Acceso Septiembre, 2016

Parodi Arróniz, A.

2015. "Proyecto Tabarca Island", online http://lafogueradetabarca.blogspot.com.es/2015/09/proyecto-tabarca-island.html, Acceso Septiembre, 2016 
Pérez Burgos, J.M.

2012. "El sueño de Nueva Tabarca. Un anhelo utópico entre el deseo y la realidad", en Canelobre, Instituto Alicantino de Cultura Juan Gil-Albert, 60: 50-63.

Ramos, A.A.; Bayle, J.

1990. "Management of living resources in the marine reserve of Tabarca island (Alicante, Spain) in Bulletin de la Société Zoologique de la France, 114: 41-48

Ramos, A.

2012. "La reserva marina de la isla de Tabarca, una realidad después del sueño", en Canelobre, Instituto

Alicantino de Cultura Juan Gil-Albert, 60: 284-297.

Soler Pascual, E.

2012. "Poblaciones idealizadas y viajeros en la España del XVIII: el caso de Nueva Tabarca" en Canelobre, Instituto Alicantino de Cultura Juan Gil-Albert, 60: 65-77.

Varela Botella, S.

2007. "Viaje a Nueva Tabarca. El territorio y la arquitectura. Breve descripción de una construcción que sobrevive a la utopía", en Semana de la arquitectura de la Comunidad valenciana, 2007. CTAA Colegio Oficial de Arquitectos de Alicante. Online http://www.ctaa.net/publio/Nueva\%20Tabarca. pdf Acceso Septiembre 2016.

\section{Notas}

Planta que crece en terrenos salados y de la que, tras su incineración, se obtiene la sosa.

Según entrevista con la policía local de Tabarca (Mayo 2016)

Propuestas de ordenación concreta de un área o sector, que debían desarrollar con detalle las propuestas de un Plan General de Ordenación del municipio y que, lógicamente, deberían haberse aprobado con antelación.

4 Es la máxima categoría de protección que se da a un bien según la Ley de patrimonio histórico español de 1985, a elementos muebles e inmuebles que por su relevancia histórica, social o su singularidad merezca protección.

5 Cálculo que acuñó Defert (1967) es un indicador del grado de especialización funcional de un espacio turístico que pone en relación la Relación porcentual entre el número de camas turísticas y la población de un determinado lugar. TFTGi= (Cti/ pi )*100, dónde: TFTGi: tasa de función turística del municipio i; CTi: número de camas turísticas totales del municipio i; Pi: población de derecho del municipio i. 